\title{
Facile Synthetic Method of Alkanethiol Spacer for Biointerface
}

\author{
Hong-Jun Cho, ${ }^{\text {a }}$ Sung Jun Park, ${ }^{a}$ Jung Won Kim, ${ }^{\mathrm{b}}$ Sang-Myung Lee, ${ }^{* c}$ Yoon-Sik Lee*a \\ a School of Chemical and Biological Engineering, Seoul National University, Seoul 151-744, Republic of Korea \\ Fax+82(2)8801604; E-mail: yslee@snu.ac.kr \\ b Department of Chemical Engineering, Kangwon National University, Kangwon-Do 245-711, Republic of Korea \\ c Department of Chemical Engineering, Kangwon National University, Kangwon-Do 200-701, Republic of Korea \\ Fax +82(33)2513658; E-mail: sangmyung@kangwon.ac.kr
}

Received: 11.09.2012; Accepted after revision: 12.11.2012

\begin{abstract}
An alkanethiol spacer which is suitable for biointerface was synthesized on 2-chlorotritylchloride (CTC) resin using solidphase synthesis method. The triethylene glycol (TEG) unit containing building block was immobilized on CTC resin followed by a coupling alkanethiol building block. After dithiothreitol (DTT) treatment and cleavage of the resulting alkanethiol spacer from the resin, the spacer was obtained in a pure form without any purification steps. The TEG-alkanethiol spacer was applied for the DNA hybridization assay on a gold surface, and proved to work well when compared to the commercial spacer.
\end{abstract}

Key words: alkanethiol, solid-phase synthesis, self-assembled monolayer, biointerface, nonspecific adsorption

Self-assembled monolayers (SAMs) are a renowned tool for both modifying and functionalizing metal or nanomaterial surfaces. Because SAM formation provides a wellappointed planar interface, it has opened the doors to fundamental studies of interfacial chemistry about the behavior of biomaterial or catalyst on solid surfaces. ${ }^{1}$ Thus, the functionalized SAM formation of alkanethiol on gold surface has been employed for biosensing interface using DNA, ${ }^{2}$ protein $^{3}$ and cells ${ }^{4}$ and for catalytic reaction. ${ }^{5}$

As these interfaces of solid surfaces are becoming increasingly important in bioanalysis, SAM molecules are required to be applicable for biocompatible surfaces. Since Whiteside et al. first introduced SAMs of oligo(ethylene glycol) (OEG)-terminated alkanethiols on gold surface, ${ }^{6,7}$ a wide variety of OEG alkanethiol spacers have been synthesized. $^{2 b, 8-12}$ Due to the presence of ethylene glycol units, OEG-terminated SAMs possess high protein resistance and the ability to reduce the nonspecific adsorption of biomolecules, even in the case of tri(ethylene glycol) (TEG)-terminated alkanethiol. ${ }^{6,13-15}$

However, it is not easy to synthesize these OEG alkanethiol derivatives. Synthesis of OEG spacers by conventional organic synthesis requires a minimum of four to five reaction steps, complicated purifications in every step and complex reaction conditions..$^{2 \mathrm{~b}, 8-10}$ Moreover, additional reaction process and purification steps are required to elongate peptides or small bioactive materials from the terminal alkanethiol. Although various attempts have

SYNLETT 2013, 24, 0020-0023

Advanced online publication: 10.12 .2012

DOI: 10.1055/s-0032-1317728; Art ID: ST-2012-U0763-L

(C) Georg Thieme Verlag Stuttgart · New York been made to reduce the reaction steps or to propose efficient methodology for the synthesis of alkanethiols, ${ }^{8,11,12}$ some limitations still exist including both complicated purification steps and low yields.

Here, we report a novel synthetic route for a TEG-alkanethiol spacer by solid-phase organic synthesis (SPOS) method utilizing building blocks. Our method provides a simple synthetic process, easy purification, as well as both high yield and purity. Using the SAMs achieved on the gold surface with the TEG-alkanethiol spacers, a DNA hybridization assay was performed to evaluate the performance of TEG-alkanethiol spacer in terms of nonspecific adsorption and the results were compared with those of 11-mercaptoundecanoic acid (MUA) and the commercial OEG spacers.

The synthetic route for TEG-alkanethiol spacers is described in Scheme 1. Before synthesis of alkanethiol spacer via SPOS, Fmoc-TEG-COOH (1), a building block which contains triethylene glycol, was easily synthesized without the need for column chromatography purification. ${ }^{16}$ Another building block, 11,11'-dithiodiundecanoic acid (3), was prepared as a thiol-protected alkyl spacer. A disulfide protection method for thiol groups was chosen to obtain free thiol under mild conditions. Then, the C-terminal of compound 1 was introduced on 2-chlorotrityl chloride (CTC) resin with DIPEA, followed by Fmoc deprotection. The existence of TEG spacer on the CTC resin was identified by FT-IR [carbonyl band: $1737 \mathrm{~cm}^{-1}$, amide band: $1664 \mathrm{~cm}^{-1}$, see Figure 1(b) in Supporting Information]. The amount of compound $\mathbf{1}$ loaded on the resin was found to be $0.32 \mathrm{mmol} / \mathrm{g}$ by Fmoc titration and elemental analysis. To couple the alkyl chain to the TEG spacer, resin 2 was treated with an excess amount of compound $\mathbf{3}$ and coupling reagents. Reduction of the resulting resin with dithiothreitol (DTT) resulted in resin 4, regardless of partial cross-linking of resin $\mathbf{2}$ with compound $\mathbf{3}$. Attachment of the alkyl spacer was monitored by ninhydrin test and was verified by the increase in the relative intensity of amide peak in the FT-IR [amide band: $1661 \mathrm{~cm}^{-}$ ${ }^{1}$, see Figure 1(c) in Supporting Information] from resin 2. Finally, the TEG-alkanethiol spacer $\mathbf{5}$ was cleaved from resin $\mathbf{4}$ and was analyzed by ESI-MS (see Figure 2 in Supporting Information). An oily product was obtained in $87 \%$ yield based on the initial loading of the TEG spacer. This strategy did not require any purification steps during synthesis, other than extraction and filtration steps. In ad- 
(a)<smiles>CC(C)(C)C(=O)CCC(=O)NCCCOCCOCCOCCCNC(=O)O</smiles><smiles>CC#CC1CCCCC1</smiles>

(b)<smiles>CC(CSSCC(C)C(=O)O)C(=O)O</smiles>

(c)

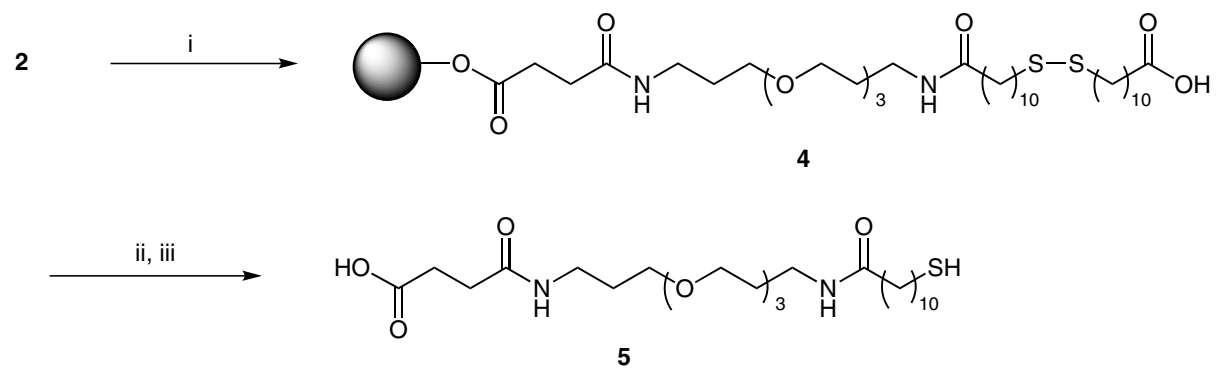

Scheme 1Reagents and conditions: (a) Preparation of TEG-loaded resin 2: (i) succinic anhydride in MeCN, 2 h, r.t.; (ii) Fmoc-OSu, DIPEA in $\mathrm{MeCN}$ and $\mathrm{H}_{2} \mathrm{O}, 2 \mathrm{~h}$, r.t.; (iii) compound 1, DIPEA in $\mathrm{CH}_{2} \mathrm{Cl}_{2}, 2$ h, r.t.; (iv) $20 \%$ piperidine (v/v) in DMF, 1 h, r.t.; (b) Synthesis of 11 , 11'dithiodiundecanoic acid (3): (i) $\mathrm{I}_{2}$, DMSO in THF; (c) Synthesis of alkylthiol linker (5): (i) compound 3, DIC, HOBt, DIPEA in NMP, 12 h, 40 ${ }^{\circ} \mathrm{C}$; (ii) DTT in NMP, 12 h, r.t.; (iii) TFA, TIS in $\mathrm{CH}_{2} \mathrm{Cl}_{2}, 1$ h, r.t.

dition, by applying a very mild cleavage condition $(1 \%$ TFA- $\mathrm{CH}_{2} \mathrm{Cl}_{2}$ ), the final compound was recovered from $\mathrm{CTC}$ resin without oxidation or other side reactions. From the result of TEG-alkanethiol spacer synthesis, our synthetic strategy, based on solid-phase organic synthesis, proved to be a simple and efficient method compared to others. Furthermore, we can easily modify the terminal functional group of the spacer by conjugating peptides or small molecules for bioassay.

Next, the TEG-alkanethiol spacer was applied for SAM formation on a gold surface. The SAM on gold surface was achieved by immersing a gold-coated silicon chip in an ethanolic solution of TEG-alkanethiol spacer. As a control experiment, another SAM on gold surface was prepared by using MUA. The SAM surfaces were characterized by X-ray photoelectron spectroscopy (XPS) and water contact angle (CA) measurement (Figure 1). Elemental analysis on the gold surface by XPS confirmed the existence of MUA (S contents) and TEG-alkanethiol (S and $\mathrm{N}$ contents). The change of hydrophilic state on SAM surfaces was measured by water contact angle. The SAM of MUA (CA: $39.4^{\circ}$ ) and TEG-alkanethiol spacer (CA: $\left.36.7^{\circ}\right)$ were more hydrophilic than a bare gold surface (CA: $63.5^{\circ}$ ) due to the negative charge on the terminal carboxyl group. Furthermore, we found that the decrease of the contact angle of the SAMs of TEG-alkanethiol spacer was attributable to ethylene glycol units through comparison with the water contact angle of the MUA sur- face. These results prove that TEG-alkanethiol spacer forms the hydrophilic SAM surface due to the carboxyl group and ethylene glycol moiety of the spacer.

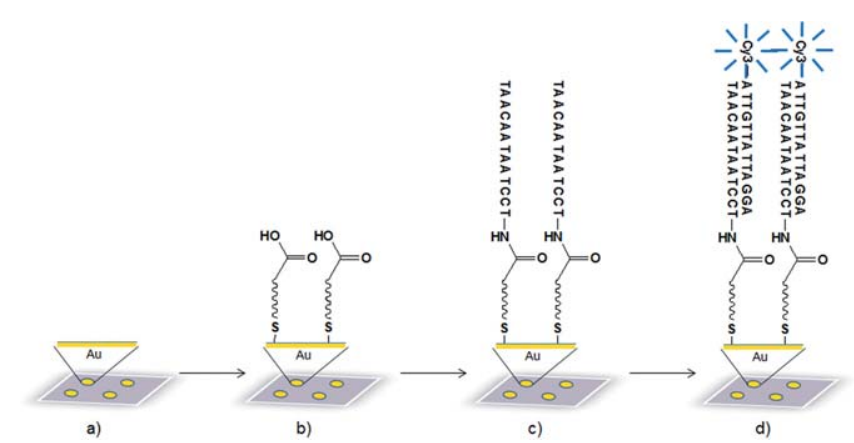

Scheme 2 DNA assay for nonspecific binding test: (a) bare gold surface; (b) SAMs of spacers on gold spots; (c) probe DNA (5'- $\mathrm{NH}_{2}^{-}$ TCCTAATAACAAT-3')-grafted surface using EDC and NHS; (d) hybridization with fluorescent labeled target DNA (Cy3-5'-ATTGTTATTAGGA-3') on the surface.

In order for the TEG-alkanethiol spacer to have proper properties for biosensor application, whether or not it exhibits the stable sensing signal and low nonspecific adsorption of the biomolecule is important. TEG-alkanethiol spacer was assessed with a DNA hybridization assay and the results were compared to those of MUA and $\mathrm{HS}-\mathrm{C}_{11}{ }^{-}$ 
(a)

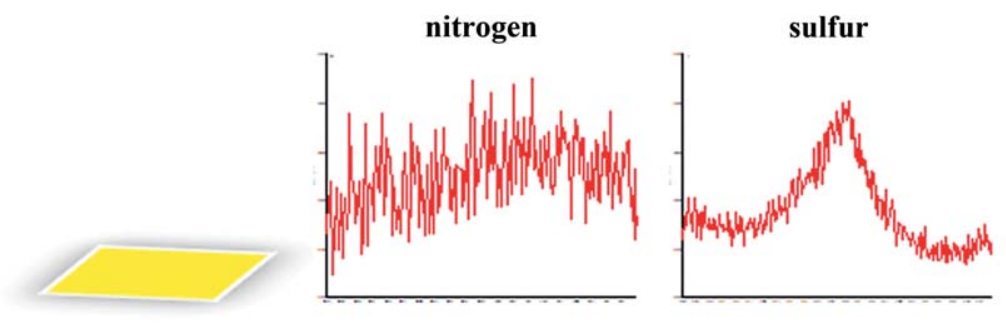

(b)
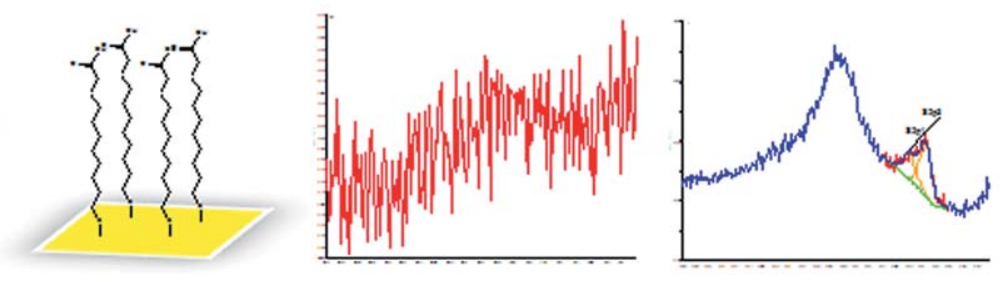

(c)
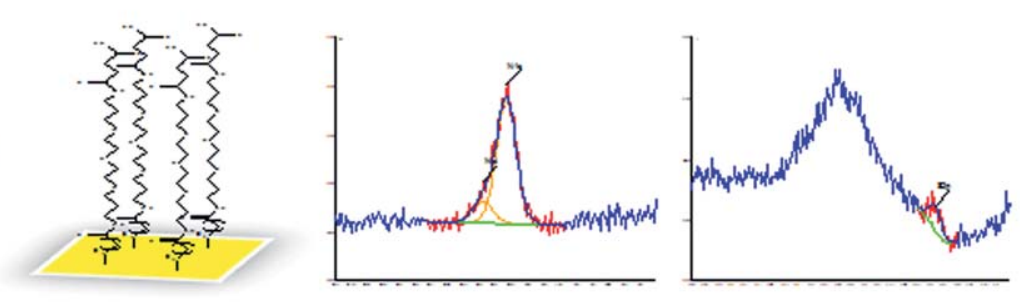
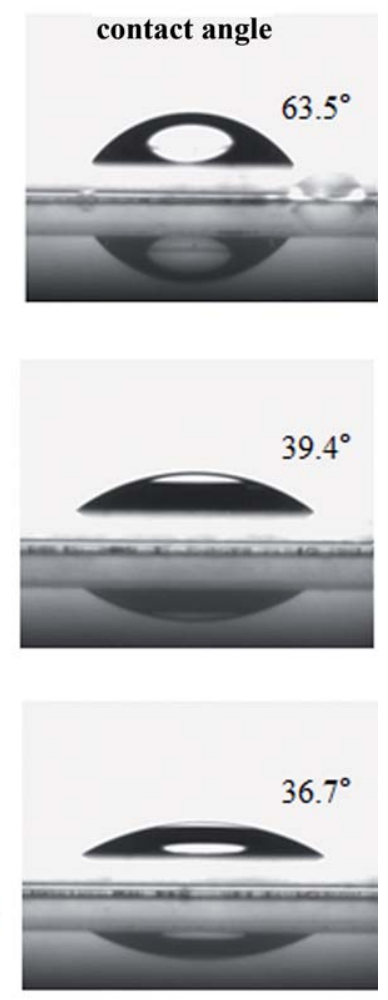

Figure 1 The characterization of the SAMs on gold surface by XPS and contact angle: (a) bare gold surface, (b) SAM surface of MUA, and (c) SAM surface of TEG-alkanethiol spacer $\mathbf{5}$.

$\mathrm{EG}_{3}-\mathrm{COOH}$ commonly used in biointerface under identical condition. The assay procedures are summarized in Scheme 2. The SAM on gold spot array for DNA detection was prepared by incubating it in ethanolic solution of TEG-alkanethiol spacer. After EDC/NHS activation on the terminal carboxyl group, the probe DNA $\left(5^{\prime}-\mathrm{NH}_{2}-\right.$ TCCTAATAACAAT-3') was immobilized on the gold spot surface. Then, fluorescence-labeled target DNA (5'Cy3-ATTGTTATTAGGA-3') of different concentrations $(1 \mathrm{mM}, 10 \mathrm{mM}$ ) which were fully complementary to the probe DNA was hybridized on the surface. As a negative control, the noncomplementary DNA (5'-Cy3GTACCTATTGCCT-3', $10 \mathrm{mM}$ ) was treated on the surface in the same manner. The specific hybridization of target DNA could be quantitatively analyzed by fluorescence intensity per unit area due to the terminal Cy3 dyes on the target DNAs. After sufficient washing steps, the fluorescence intensities from three kinds of SAMs on gold spots were measured by a fluorescence scanner.

As shown in Figure 2, the fluorescence intensities on

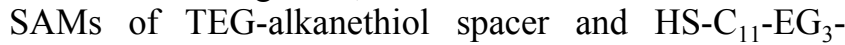
$\mathrm{COOH}$ were well correlated with the concentrations of target DNA. In contrast, the fluorescence intensity on SAM of MUA displayed inconsistent patterns as the concentration of target DNA increased with wide error ranges. In control experiment, the amount of nonspecific target DNA adsorption on SAM of MUA was much higher than others. These results show that OEGs of TEG-alkanethiol

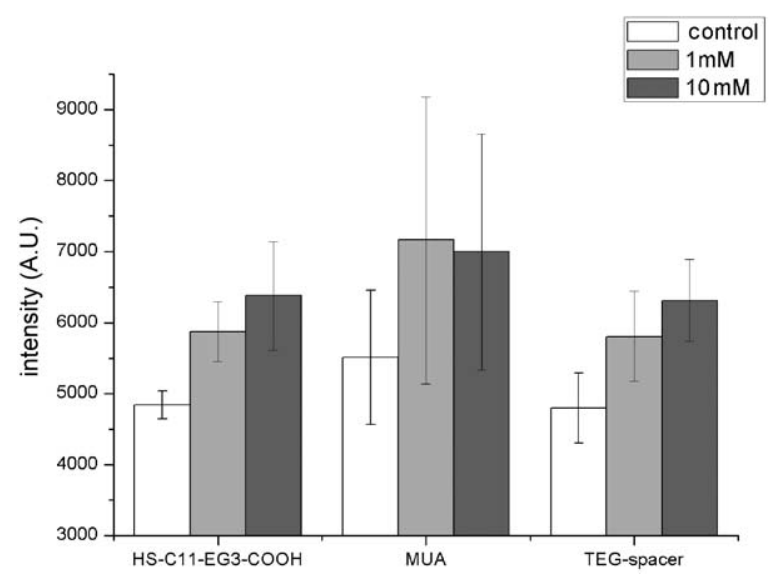

Figure 2 The results of fluorescence-based DNA hybridization assay from three kinds of SAMs (HS- $\mathrm{C}_{11}-\mathrm{EG}_{3}-\mathrm{COOH}, \mathrm{MUA}$ and TEG-alkanethiol spacer from left to right) on gold spots. Noncomplementary DNA $(10 \mathrm{mM})$ as a control and complementary DNA (1 mM and 10 $\mathrm{mM}$ ) were used for the assay.

spacer and $\mathrm{HS}-\mathrm{C}_{11}-\mathrm{EG}_{3}-\mathrm{COOH}$ contribute to stabilizing the fluorescence signals by specific DNA binding and reducing nonspecific adsorption on SAM surface. The performance of SAMs of TEG-alkanethiol spacer was almost similar to that of commercially available $\mathrm{HS}-\mathrm{C}_{11}-\mathrm{EG}_{3^{-}}$ $\mathrm{COOH}$ spacer. As a result, the TEG-alkanethiol spacer that we facilely and efficiently synthesized is a reliable material to form SAMs for biointerface. 
In conclusion, TEG-alkanethiol spacer for biointerface was synthesized by a mild and simple synthetic method based on SPOS. Using building blocks prepared by simple procedures, and without complicated purification steps, we efficiently obtained a TEG-alkanethiol spacer from CTC resin. The results of DNA assay on SAM of TEG-alkanethiol demonstrate that the TEG-alkanethiol spacer provided a biocompatible interface with reducing nonspecific binding. We proved that the solid-phase synthetic method is a valuable tool for the synthesis of alkanethiol spacers for biointerface.

\section{Acknowledgment}

This study was supported by a 2011 Research Grant from the Kangwon National University.

Supporting Information for this article is available online at http://www.thieme-connect.com/ejournals/toc/synlett.

\section{References}

(1) Love, J. C.; Estroff, L. A.; Kriebel, J. K.; Nuzzo, R. G.; Whitesides, G. M. Chem. Rev. 2005, 105, 1103.

(2) (a) Thiel, A. J.; Frutos, A. G.; Jordan, C. E.; Corn, R. M.; Smith, L. M. Anal. Chem. 1997, 69, 4948. (b) Zhou, D. J.; Ying, L. M.; Hong, X.; Hall, E. A.; Abell, C.; Klenerman, D. Langmuir 2008, 24, 1659. (c) Peeters, S.; Stakenborg, T.; Reekmans, G.; Laureyn, W.; Lagae, L.; Van Aerschot, A.; Van Ranst, M. Biosens. Bioelectron. 2008, 24, 72. (d) Ferapontova, E. E.; Hansen, M. N.; Saunders, A. M.; Shipovskov, S.; Sutherland, D. S.; Gothelf, K. V. Chem. Commun. 2010, 46, 1836.

(3) (a) Sigal, G. B.; Bamdad, C.; Barberis, A.; Strominger, J.; Whitesides, G. M. Anal. Chem. 1996, 68, 490. (b) Houseman, B. T.; Huh, J. H.; Kron, S. J.; Mrksich, M. Nat. Biotechnol. 2002, 20, 270. (c) Su, J.; Mrksich, M.
Angew. Chem. Int. Ed. 2002, 41, 4715. (d) Hahn, C. D.; Leitner, C.; Weinbrenner, T.; Schlapak, R.; Tinazli, A.; Tampe, R.; Lackner, B.; Steindl, C.; Hinterdorfer, P.; Gruber, H. J.; Holzl, M. Bioconjugate Chem. 2007, 18, 247.

(4) (a) Mrksich, M.; Chen, C. S.; Xia, Y. N.; Dike, L. E.; Ingber, D. E.; Whitesides, G. M. Proc. Natl. Acad. Sci. U.S.A. 1996, 93, 10775. (b) Roberts, C.; Chen, C. S.; Mrksich, M.; Martichonok, V.; Ingber, D. E.; Whitesides, G. M. J. Am. Chem. Soc. 1998, 120, 6548. (c) Mrksich, M. Chem. Soc. Rev. 2000, 29, 267. (d) Arima, Y.; Iwata, H. J. Mater. Chem. 2007, 17, 4079.

(5) (a) Bartz, M.; Kuther, J.; Seshadri, R.; Tremel, W. Angew. Chem. Int. Ed. 1998, 37, 2466. (b) Li, H.; Luk, Y. Y.; Mrksich, M. Langmuir 1999, 15, 4957. (c) Weck, M.; Jackiw, J. J.; Rossi, R. R.; Weiss, P. S.; Grubbs, R. H. J. Am. Chem. Soc. 1999, 121, 4088.

(6) Prime, K. L.; Whitesides, G. M. Science 1991, 252, 1164.

(7) Palegrosdemange, C.; Simon, E. S.; Prime, K. L.; Whitesides, G. M. J. Am. Chem. Soc. 1991, 113, 12.

(8) Houseman, B. T.; Mrksich, M. J. Org. Chem. 1998, 63, 7552.

(9) Valiokas, R.; Svedhem, S.; Svensson, S. C. T.; Liedberg, B. Langmuir 1999, 15, 3390.

(10) Svedhem, S.; Hollander, C. A.; Shi, J.; Konradsson, P.; Liedberg, B.; Svensson, S. C. T. J. Org. Chem. 2001, 66, 4494.

(11) Prats-Alfonso, E.; Garcia-Martin, F.; Bayo, N.; Cruz, L. J.; Pla-Roca, M.; Samitier, J.; Errachid, A.; Albericio, F. Tetrahedron 2006, 62, 6876.

(12) Tseng, M. C.; Chang, Y. P.; Chu, Y. H. Anal. Biochem. 2007, 371, 1 .

(13) Deng, L.; Mrksich, M.; Whitesides, G. M. J. Am. Chem. Soc. 1996, $118,5136$.

(14) Harder, P.; Grunze, M.; Dahint, R.; Whitesides, G. M.; Laibinis, P. E. J. Phys. Chem. B 1998, 102, 426.

(15) Tanaka, M.; Sawaguchi, T.; Sato, Y.; Yoshioka, K.; Niwa, O. Tetrahedron Lett. 2009, 50, 4092.

(16) Song, A. M.; Wang, X. B.; Zhang, J. H.; Marik, J.; Lebrilla, C. B.; Lam, K. S. Bioorg. Med. Chem. Lett. 2004, 14, 161. 